\title{
Building a national organization of future emergency medicine physicians
}

\author{
Jason R. Frank, MD
}

$\mathrm{R}$ esident interest in emergency medicine $(\mathrm{EM})$ is on the rise. Each year, postgraduate matches add to the ranks of Canadian EM residents, and the Canadian Association of Emergency Physicians (CAEP) Residents' Section (RS) continues to expand. The numbers are inspiring. This year, 16 residents accepted Royal College EM postgraduate year-1 (PGY-1) slots. Many more began their CCFP(EM) PGY-3 year, and this doesn't include the residents who matched separately to EM training programs in Quebec. At the same time, the Canadian Resident Matching Service (CaRMS) matched about 433 new Family Medicine residents and 63 new Pediatrics residents. A significant number of these groups will also go on to develop interests and skills in EM.

There is a large and expanding pool of EM residents. This expansion has fuelled parallel growth in the CAEP Residents' Section. As of January 1999, the Residents' Section's 161 resident members and 13 medical student members accounted for $13 \%$ of CAEP membership and included a significant proportion of all Canadian EM residents. If we can harness this talent and enthusiasm, our numbers give us an unprecedented opportunity for development of the Canadian EM residency experience. Consider that EM residents share many common

University of Toronto, Toronto, Ont. interests, including an enjoyment of EM work, a desire to become the most effective clinicians possible, an interest in maximizing residency experiences, an interest in working toward an optimal practice opportunity, the need to improve our understanding of EM research, and a stake in furthering the specialty of EM in Canada.

Through the CAEP RS, we can build a national network of EM residents and help make the most of our residency education. We should expand our role in, and take full advantage of CJEM, the CAEP annual conference, and general CAEP activities. CJEM is a forum in which residents can discuss important EM issues, communicate our concerns to other emergency physicians, share our residency experiences, and proudly publish our research. The annual conference provides an opportunity to network with other residents, present research projects, and - as of this October - play hockey against EM faculty! Through CAEP's Residents' Section, we can create national projects of interest to EM residents and help guide the evolution of Canadian EM.

Correspondence to: jfrank@istar.ca

\section{A Call for Papers}

The Resident Issues section of CJEM is a forum for discussion of topics of particular relevance to emergency medicine residents in Canada. CJEM extends a special invitation for submissions by individuals and groups of authors of papers on the following topics:

- Reports on curriculum developments in EM residencies

- Resident research

- Featured electives

- Opinion pieces on a resident issue

Residents, this is your section of CJEM and your opportunity to publish your ideas and analysis!

For submissions and further information, contact:

Grant Innes, MD

Editor-in-Chief, CJEM

ginnes@interchange.ubc.ca
Jason Frank, MD

Resident Issues Section Editor, CJEM

jfrank@istar.ca 